\title{
Differences in risk factors between patterns of recurrence in patients after curative resection for advanced gastric carcinoma
}

\author{
Yoshitsugu Nakanishi ${ }^{1,2^{*}}$, Masanori Ohara ${ }^{1}$, Hiromitsu Domen ${ }^{1,2}$, Toshiaki Shichinohe ${ }^{2}$, Satoshi Hirano ${ }^{2}$ \\ and Masanori Ishizaka ${ }^{1}$
}

\begin{abstract}
Background: Recurrence patterns in patients who have undergone curative gastrectomy for advanced gastric carcinoma can be classified as peritoneal, hematogenous, or lymphatic. The aim of this study was to clarify differences in risk factors between these different types of recurrence pattern.

Methods: Postoperative courses, including sites of recurrence and periods between surgery and recurrence, of patients who had undergone curative gastrectomy for advanced gastric carcinoma (more than pT2 invasion) were surveyed in detail. Clinicopathological factors were examined as potential independent risk factors for each recurrence pattern, based on recurrence-free survival, using multivariate analysis.

Results: Multivariate analysis identified depth of tumor invasion (pT4 vs. pT2/3; hazard ratio (HR), 7.05; $P<0.001$ ), number of lymph node metastases (pN2/3 vs. pNO/1; HR, 4.02; $P=0.001$ ), and histological differentiation (G3/4 vs. $\mathrm{G} 1 / 2 ; \mathrm{HR}, 2.22 ; P=0.041$ ) as independent risk factors for peritoneal metastasis. The number of lymph node metastases $(H R, 26.21 ; P<0.001)$ and venous vessel invasion $(H R, 5.09 ; P=0.001)$ were identified as independent risk factors for hematogenous metastasis. The number of lymph node metastases (HR, 6.00; $P=0.007)$ and depth of tumor invasion ( $H R, 4.70 ; P=0.023)$ were identified as independent risk factors for lymphatic metastasis.

Conclusions: This study clarified differences in risk factors between various patterns of recurrence. Careful examination of risk factors could help prevent oversight of recurrences and improve detection of recurrences during follow-up. The number of lymph node metastases represents an independent risk factor for all three patterns of recurrence; thus, patients with multiple lymph node metastases warrant particular attention.
\end{abstract}

Keywords: Gastric carcinoma, Patterns of recurrence, Prognosis, Risk factor

\section{Background}

Even after performing curative surgical resection, death from recurrence is frequent among patients with advanced gastric carcinoma. However, early detection of recurrence sites is sometimes difficult. One reason for this is that recurrence can show various patterns. Recurrence patterns in patients who have undergone curative surgical resection for advanced gastric carcinoma can be classified as peritoneal, hematogenous, or lymphatic

\footnotetext{
* Correspondence: y.nakanishi@mac.com

'Department of Surgery, National Hospital Organization, Hakodate Hospital,

18-16 Kawahara-cho, Hakodate 041-8512, Japan

${ }^{2}$ Second Department of Gastroenterological Surgery, Hokkaido University

Graduate School of Medicine, North 15, West 7 Kita-ku, Sapporo 060-8638, Japan
}

\section{Biomed Central}

(c) 2013 Nakanishi et al.; licensee BioMed Central Ltd. This is an Open Access article distributed under the terms of the Creative Commons Attribution License (http://creativecommons.org/licenses/by/2.0), which permits unrestricted use, distribution, and reproduction in any medium, provided the original work is properly cited.

metastases. Clarification of the differences in risk factors between these patterns of recurrence may be helpful in postoperative follow-up to ensure that recurrences are not missed and to allow additional therapy, including chemo- or radiotherapy, to be initiated early in the recurrence phase.

The aim of this study, therefore, was to clarify differences in risk factors between these three recurrence patterns among patients who had undergone curative resection for advanced gastric carcinoma. 


\section{Methods \\ Patients}

Patients with synchronous primary neoplasms of other organs or who had undergone neoadjuvant chemotherapy were excluded from the study. A total of 132 patients (87 men, 45 women) who had undergone surgical curative resection and had been pathologically diagnosed with advanced gastric carcinoma (defined as carcinoma extending more deeply than the muscularis propria) between April 1999 and December 2011 at the National Hospital Organization at Hakodate Hospital, Hakodate, Japan, were registered in the study. All these patients showed negative results on intra-operative peritoneal cytology. The median age at the time of surgery was 69 years (range, 30 to 92 years). Surgical procedures for these patients involved total gastrectomy for 53 patients, distal gastrectomy for 70, proximal gastrectomy for 6 , and pancreaticoduodenectomy for 3. The extent of lymph node dissection was D2 level in 71 patients and below D2 in 61, according to the 2010 Japanese gastric cancer treatment guidelines [1]. Adjuvant treatment after surgical resection was administered at the discretion of the individual surgeon. A total of 61 patients (including 3 of 19 patients in stage 1, 15 of 51 in stage 2, and 43 of 61 in stage 3 according to the TNM Classification of Malignant Tumors [2]) received oral administration of S-1 or UFT for approximately 1 year, or until side effects became too strong to tolerate.

\section{Postoperative follow-up}

Most patients received regular follow-up sessions every 3 months. At each visit, a clinical examination, hematological analysis (including tumor marker assays for carcinoembryonic antigen and carbohydrate antigen 19-9), and chest and abdominal radiography were performed. Digestive endoscopy was performed annually. Follow-up ended in March 2012. The median survival period for all patients was 32 months (range, 1 to 157 months).

Computed tomography of the abdomen was performed every 6 months or on suspicion of clinical recurrence, including when an increase in tumor markers above pathological levels was seen. Bone scintigraphy was used for suspected bone metastasis. If an intestinal obstruction was not improved by long tube insertion, the patient was examined for peritoneal dissemination and underwent surgery if necessary.

\section{Clinicopathological factors}

This study examined eight clinicopathological factors as candidate risk factors for recurrence after curative resection of advanced gastric carcinoma: extent of the primary tumor (pT2/3 vs. pT4); number of metastatic lymph nodes ( $\mathrm{pN} / 1$ vs. $\mathrm{pN} 2 / 3$ ); histopathological grading (G1/2, including papillary carcinoma, vs. G3/4, including signet ring cell carcinoma, mucinous adenocarcinoma, in accordance with the TNM Classification of Malignant Tumors [2]); venous invasion; lymphatic vessel invasion; sex; age ( $<70$ years vs. $\geq 70$ years); and extent of systematic lymphadenectomy (D2 or less than D2, according to Japanese gastric cancer treatment guidelines 2010 [1]). In this study, performance of adjuvant chemotherapy was not examined as a candidate risk factor of recurrence, because this factor correlated with other factors (pT4 and $\mathrm{pN} 2 / 3$ ).

\section{Prognostic factors for overall survival}

Risk factors for overall survival were examined using univariate and multivariate analysis to compare them for each pattern of recurrence.

\section{Examinations of risk factors according to patterns of recurrence}

The type of recurrence was classified on the basis of imaging studies or intra-operative and biopsy findings in patients who underwent re-operation. The incidence of recurrence depends on the time from surgical resection. We therefore examined for risk factors associated with the time of recurrence-free survival (RFS):

1. RFS was defined as the interval between completion of surgery and recurrence.

2. For patients with two or three recurrence patterns detected asynchronously, RFS for all recurrence patterns was defined as the interval between surgery and the first recurrence pattern.

3. Patients with two or three recurrence patterns detected simultaneously were classified as showing all the recurrence patterns detected.

4. In an examination for one pattern of recurrence, data from patients with only the other recurrence patterns were censored as of the date of occurrence of the other recurrence patterns.

5. Data for patients who did not experience recurrence were censored as of the date of the final observation.

6. Data for patients who died without recurrence were censored as of the date of death.

\section{Statistical analysis}

Survival curves were constructed using the KaplanMeier method and differences in overall survival and RFS on univariate analysis were evaluated using the logrank test. The Cox proportional hazards model was used to perform multivariate analysis. All tests were twosided; values of $P<0.05$ were considered statistically significant. 


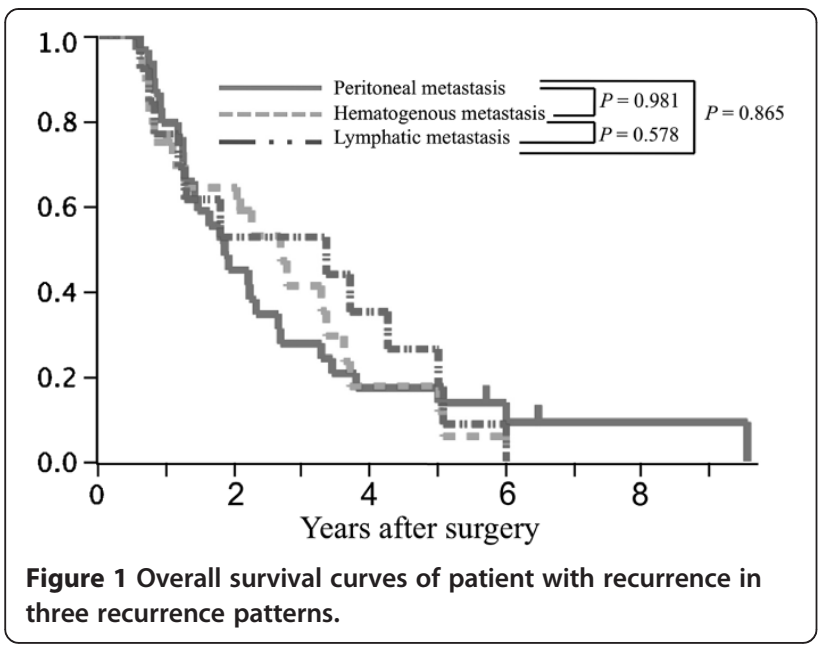

\section{Results}

Recurrence patterns

Among the 132 patients who underwent curative resection for advanced gastric carcinoma, 66 were alive without recurrence and 6 were alive with recurrence of gastric carcinoma, as of March 2012, while 21 patients had died of other diseases without evident recurrence of gastric carcinoma and 39 had died of recurrent gastric carcinoma.

Of the 45 patterns of recurrence, peritoneal-only, hematogenous-only, lymphatic-only, all three patterns combined, hematogenous with lymphatic, peritoneal with hematogenous, and peritoneal with lymphatic patterns were seen in $21,8,2,4,5,2$, and 3 patients, respectively. Overall survival curves after surgical resection with the three recurrence patterns are shown in Figure 1. The median overall survival period for peritoneal, hematogenous, and lymphatic metastasis patterns was 22.6 months (range, 7 to 115 months), 32.5 months ( 8 to 72 months), and 40.5 months ( 8 to 72 months), respectively. No statistical difference was seen between the three recurrence patterns $(P=0.939)$.

\section{Prognostic factors in overall survival}

The impacts of clinicopathological variables on overall survival in all 132 patients are shown in Table 1. Histological differentiation, depth of tumor invasion, number

Table 1 Univariate and multivariate analyses of overall survival

\begin{tabular}{|c|c|c|c|c|}
\hline Variable & $n$ & $\begin{array}{c}\text { Survival rate at } 5 \\
\text { years (\%) }\end{array}$ & Univariate $P$ & $\begin{array}{c}\text { Multivariate } P \text { relative } \\
\text { risk ( } 95 \% \text { confidence interval) }\end{array}$ \\
\hline Age (years) & & & 0.104 & \\
\hline$<70$ & 74 & 61.7 & & \\
\hline$\geq 70$ & 58 & 45.2 & & \\
\hline Sex & & & 0.165 & \\
\hline Male & 87 & 58.8 & & \\
\hline Female & 45 & 47.0 & & \\
\hline Lymphadenectomy & & & 0.647 & \\
\hline$<\mathrm{D} 2$ & 61 & 56.2 & & \\
\hline D2 & 71 & 54.8 & & \\
\hline Histological differentiation & & & 0.002 & 0.006 \\
\hline G1 or G2 & 58 & 70.7 & & 1 \\
\hline G3 or G4 & 74 & 41.2 & & 2.15 (1.23 to 3.85$)$ \\
\hline Depth of tumor invasion & & & $<0.001$ & 0.040 \\
\hline pT2 or pT3 & 64 & 77.2 & & 1 \\
\hline pT4 & 68 & 35.6 & & 1.85 (1.03 to 3.47$)$ \\
\hline Number of lymph node metastases & & & $<0.001$ & $<0.001$ \\
\hline pNo or pN1 & 74 & 72.8 & & 1 \\
\hline $\mathrm{pN} 2$ or $\mathrm{pN} 3$ & 58 & 36.5 & & 2.71 (1.53 to 4.98$)$ \\
\hline Lymphatic invasion & & & 0.016 & \\
\hline Negative & 45 & 70.7 & & \\
\hline Positive & 87 & 48.1 & & \\
\hline Venous invasion & & & 0.026 & \\
\hline Negative & 84 & 62.7 & & \\
\hline Positive & 48 & 39.4 & & \\
\hline
\end{tabular}


of lymph node metastases, lymphatic vessel invasion, and venous vessel invasion were identified as prognostic factors for overall survival on univariate analysis $(P=0.020, P<0.001, P<0.001, P=0.016$, and $P=$ 0.026 , respectively). On multivariate analysis, histological differentiation, depth of primary tumor invasion, and number of lymph node metastases were identified as independent factors affecting overall survival $(P=0.006$, $P=0.040$, and $P<0.001$, respectively).

\section{Risk factors for recurrence patterns \\ Peritoneal metastasis}

The median RFS for the 30 patients with peritoneal metastasis was 14.5 months (range, 3.4 to 64.2 months). The impacts of clinicopathological variables on the RFS of peritoneal recurrence are shown in Table 2. On univariate analysis, histological differentiation, depth of tumor invasion, and number of lymph node metastases were identified as risk factors for peritoneal metastasis ( $P=0.022, P<0.001$, and $P<0.001$, respectively). On multivariate analysis, histological differentiation, depth of tumor invasion, and number of lymph node metas- tases represented independent risk factors associated with peritoneal metastasis $(P=0.041, P<0.001$, and $P=0.001$, respectively).

\section{Hematogenous metastasis}

Recurrence sites in the 19 patients with hematogenous recurrence were the liver in ten patients $(52.6 \%)$, bone in four $(21.1 \%)$, pleura in three $(15.8 \%)$, lungs in three $(15.8 \%)$, brain in two (10.5\%), and intramural residual stomach, non-resected stump or site of anastomosis, in two (10.5\%). Some patients had recurrence in more than one site.

The median RFS of the 19 patients with peritoneal metastasis was 14.2 months (range, 2.1 to 59.8 months). The impacts of clinicopathological variables on RFS for hematogenous metastasis are shown in Table 3. On univariate analysis, depth of tumor invasion, number of lymph node metastases, lymphatic vessel invasion, and venous invasion were identified as risk factors for hematogenous metastasis $(P=0.009, P<0.001$, $P=0.004$, and $P<0.001$, respectively). On multivariate analysis, the number of lymph node metastases and

Table 2 Univariate and multivariate analyses of recurrence-free survival for peritoneal metastasis

\begin{tabular}{|c|c|c|c|c|}
\hline Variables & $n$ & $\begin{array}{c}\text { Cumulative recurrence } \\
\text { rate at } 5 \text { years }(\%)\end{array}$ & Univariate $P$ & $\begin{array}{l}\text { Multivariate } P \text { relative risk } \\
\text { (95\% confidence interval) }\end{array}$ \\
\hline Age (years) & & & 0.460 & \\
\hline$<70$ & 74 & 30.6 & & \\
\hline$\geq 70$ & 58 & 30.0 & & \\
\hline Sex & & & 0.126 & \\
\hline Male & 87 & 23.6 & & \\
\hline Female & 45 & 48.7 & & \\
\hline Lymphadenectomy & & & 0.595 & \\
\hline$<\mathrm{D} 2$ & 61 & 29.0 & & \\
\hline D2 & 71 & 33.0 & & \\
\hline Histological differentiation & & & 0.022 & 0.041 \\
\hline G1 or G2 & 58 & 20.4 & & 1 \\
\hline G3 or G4 & 74 & 42.3 & & 2.22 (1.03 to 5.17$)$ \\
\hline Depth of tumor invasion & & & $<0.001$ & $<0.001$ \\
\hline pT2 or pT3 & 64 & 8.0 & & 1 \\
\hline pT4 & 68 & 53.6 & & 7.05 (2.42 to 30.05$)$ \\
\hline Number of lymph node metastases & & & $<0.001$ & 0.001 \\
\hline $\mathrm{pNO}$ or pN1 & 74 & 13.2 & & 1 \\
\hline $\mathrm{pN} 2$ or $\mathrm{pN} 3$ & 58 & 53.7 & & $4.02(1.03$ to 5.17$)$ \\
\hline Lymphatic invasion & & & 0.120 & \\
\hline Negative & 45 & 23.1 & & \\
\hline Positive & 87 & 36.0 & & \\
\hline Venous invasion & & & 0.441 & \\
\hline Negative & 84 & 29.1 & & \\
\hline Positive & 48 & 34.6 & & \\
\hline
\end{tabular}


Table 3 Univariate and multivariate analyses of recurrence-free survival for hematogenous metastasis

\begin{tabular}{|c|c|c|c|c|}
\hline Variables & $n$ & $\begin{array}{c}\text { Cumulative recurrence } \\
\text { rate at 5-year (\%) }\end{array}$ & Univariate $P$ & $\begin{array}{l}\text { Multivariate } P \text { relative risk } \\
(95 \% \text { confidence interval) }\end{array}$ \\
\hline Age (years) & & & 0.309 & \\
\hline$<70$ & 74 & 27.1 & & \\
\hline$\geq 70$ & 58 & 13.5 & & \\
\hline Sex & & & 0.505 & \\
\hline Male & 87 & 20.2 & & \\
\hline Female & 45 & 28.3 & & \\
\hline Lymphadenectomy & & & 0.234 & \\
\hline$<\mathrm{D} 2$ & 61 & 20.9 & & \\
\hline D2 & 71 & 25.1 & & \\
\hline Histological differentiation & & & 0.094 & \\
\hline G1 or G2 & 72 & 14.5 & & \\
\hline G3 or G4 & 59 & 31.2 & & \\
\hline Depth of tumor invasion & & & 0.009 & 0.708 \\
\hline pT2 or pT3 & 64 & 13.0 & & 1 \\
\hline pT4 & 68 & 33.1 & & 1.23 (0.43 to 4.08$)$ \\
\hline Number of lymph node metastases & & & $<0.001$ & $<0.001$ \\
\hline $\mathrm{pNO}$ or pN1 & 74 & 2.0 & & 1 \\
\hline $\mathrm{pN} 2$ or $\mathrm{pN} 3$ & 58 & 47.7 & & 26.21 (3.66 to 581.73 ) \\
\hline Lymphatic invasion & & & 0.004 & 0.982 \\
\hline Negative & 45 & 3.3 & & 1 \\
\hline Positive & 87 & 32.5 & & 1.03 (0.14 to 22.26) \\
\hline Venous invasion & & & $<0.001$ & 0.001 \\
\hline Negative & 84 & 12.9 & & 1 \\
\hline Positive & 48 & 49.3 & & 5.09 (1.89 to 14.87$)$ \\
\hline
\end{tabular}

venous vessel invasion represented independent risk factors for hematogenous metastasis $(P<0.001$ and $P=0.001$, respectively).

\section{Lymphatic metastasis}

The median RFS for the 14 patients with lymphatic metastasis (including 3 patients with lymphangiosis carcinomatosa) was 15.3 months (range, 4.2 to 59.8 months). The impacts of clinicopathological variables on RFS for lymphatic metastasis are shown in Table 4. On univariate analysis, depth of tumor invasion and number of lymph node metastases were identified as risk factors for lymphatic metastasis $(P=0.001$, and $P<0.001$, respectively). On multivariate analysis, depth of tumor invasion and number of lymph node metastases represented independent risk factors for lymphatic metastasis ( $P=0.023$ and $P=0.007$, respectively).

\section{Discussion}

This study examined differences in risk factors between various patterns of recurrence in patients who underwent surgical curative resections for advanced gastric carcinoma. As a result, independent risk factors for each recurrence pattern were identified as follows. For peritoneal metastasis, depth of tumor invasion, number of lymph node metastases, and histological differentiation were identified. For hematogenous metastasis, number of lymph node metastases, and venous vessel invasion were identified. For lymphatic metastasis, depth of tumor invasion, and number of lymph node metastases were identified.

Seeding of cancer cells into the abdominal cavity represents the first step in peritoneal metastasis. This means that pT4 can reasonably be considered an independent risk factor for peritoneal metastasis, as previously reported [3-6]. Histological differentiation was also detected as a risk factor for peritoneal metastasis in some reports [4,6-9]. Although some reports have described lymph node metastasis as an independent risk factor for peritoneal metastasis, as in our result $[4,5,10-12]$, the role of lymph node metastasis in peritoneal metastasis has been unclear. However, because peritoneal recurrence occurred in patients with cancer limited to the gastric mucosa or submucosa but with 
Table 4 Univariate and multivariate analyses of recurrence-free survival for lymphatic metastasis

\begin{tabular}{|c|c|c|c|c|}
\hline Variables & $n$ & $\begin{array}{l}\text { Cumulative recurrence } \\
\text { rate at 5-year (\%) }\end{array}$ & Univariate $P$ & $\begin{array}{l}\text { Multivariate } P \text { relative risk } \\
(95 \% \text { confidence interval) }\end{array}$ \\
\hline Age (years) & & & 0.949 & \\
\hline$<70$ & 74 & 21.2 & & \\
\hline$\geq 70$ & 58 & 12.3 & & \\
\hline Sex & & & 0.609 & \\
\hline Male & 87 & 16.9 & & \\
\hline Female & 45 & 23.0 & & \\
\hline Lymphadenectomy & & & 0.492 & \\
\hline$<\mathrm{D} 2$ & 61 & 20.4 & & \\
\hline D2 & 71 & 18.5 & & \\
\hline Histological differentiation & & & 0.074 & \\
\hline G1 or G2 & 58 & 14.6 & & \\
\hline G3 or G4 & 74 & 27.9 & & \\
\hline Depth of tumor invasion & & & 0.001 & 0.023 \\
\hline pT2 or pT3 & 64 & 7.7 & & 1 \\
\hline pT4 & 68 & 31.2 & & $4.70(1.21$ to 31.28$)$ \\
\hline Number of lymph node metastases & & & $<0.001$ & 0.007 \\
\hline pNo or pN1 & 74 & 5.0 & & 1 \\
\hline $\mathrm{pN} 2$ or $\mathrm{pN} 3$ & 58 & 38.1 & & 6.00 (1.56 to 39.83$)$ \\
\hline Lymphatic invasion & & & 0.073 & \\
\hline Negative & 45 & 8.4 & & \\
\hline Positive & 87 & 24.8 & & \\
\hline Venous invasion & & & 0.122 & \\
\hline Negative & 84 & 14.9 & & \\
\hline Positive & 48 & 35.3 & & \\
\hline
\end{tabular}

lymph node metastasis, invasion of the lymphatic system by cancer cells has been suggested as the mechanism underlying peritoneal recurrence $[13,14]$. Moreover, injury to the lymphatic system during operative procedures in patients with highly extensive metastatic lymph nodes may allow the spread of viable cancer cells into the peritoneal cavity [12].

The first step in hematogenous metastasis is invasion of cancer cells into the lumen of the venous circulation. Our finding of vessel invasion as an independent factor for hematogenous metastasis is reasonable. The same result has been reported from other institutions $[15,16]$. However, vessel invasion is not incorporated as a factor in the Union for International Cancer Control (UICC) staging criteria or the Japanese classification of gastric carcinoma. Attention should thus be given to hematogenous recurrence in patients showing vessel invasion, even if the tumor stage is otherwise comparatively low. Conversely, the number of lymph node metastases might be an independent risk factor for hematogenous metastasis because of the connection of lymphatic channels to the systemic circulation via the thoracic duct. Noguchi et al. [16] reported venous invasion and lymph node metastasis as risk factors for liver metastasis. Kodera et al. [17] reported lymph node metastasis as a risk factor for bone metastasis.

With regard to lymphatic metastasis, the number of lymph node metastases and depth of tumor invasion represented independent risk factors. In this study, however, lymphatic vessel invasion was not identified as a risk factor for lymphatic metastasis, perhaps for the following reasons. First, cancer cells flow through lymphatic vessels to distant vessels. Cancer cells invading lymphatic vessels are therefore sometimes not detected in resected specimens. Second, lymphatic vessels are sometimes difficult to distinguish from the venous vasculature. In addition, some lymphatic vessels are thought to be destroyed by invasion of cancer cells, so pathologists cannot always detect lymphatic vessel invasions correctly. Third, if the number of cancer cells invading lymphatic vessels is small, the invasion might not be reflected in the patient prognosis. In addition, quantifying the grade of lymphatic vessel invasion objectively is difficult. However, the number of lymph node 
metastases reflects outflow of cancer cells into lymphatic vessels. In our study, the number of lymph node metastases was stratified into N0/N1 or N2/N3. This stratification of lymph node metastasis may be considered to reflect the amount of cancer cells invading lymphatic networks better than the presence or absence of lymphatic vessel invasion.

As with our result, some reports have described the number of lymph node metastases as a risk factor for lymphatic metastasis [12,14]. The identification of pT4 as an independent factor for lymphatic metastasis might reflect cancer cell invasion into the entire subserosal layer through the abundant lymphatic vessels.

The status of lymph node metastasis has been identified as the most important prognostic factor in patients undergoing gastrectomy $[3,4,7,18-21]$. This is reflected in the fact that the number of lymph node metastases represented an independent prognostic factor for all three patterns of recurrence in the present study. As mentioned previously, the number of lymph node metastases might reflect the amount of cancer cells in lymphatic channels in the peritoneum and both the greater and lesser omentum. Preoperative neoadjuvant chemotherapy for patients with a strong indication of lymph node metastases might therefore be acceptable to reduce seeding of cancer cells into the abdominal cavity as the result of surgical procedures. However, no randomized studies have yet addressed the survival benefits of this approach [1]. Randomized controlled trials of neoadjuvant therapy for patients with lymph node metastasis are thus needed to clarify means of achieving better prognosis in patients undergoing curative resection.

\section{Conclusions}

Risk factors for recurrence after curative gastrectomy for advanced gastric carcinoma differ between patterns of recurrence. By paying more attention to the specific risk factors of recurrence present in patients, the likelihood of missing sites of recurrence could be decreased and recurrences identified earlier. This would allow appropriate treatment to be initiated more quickly for patients with recurrence. In addition, the status of lymph node metastasis contributed to all patterns of recurrence, even peritoneal metastasis. For patients in whom lymph node metastasis is suspected preoperatively, neoadjuvant therapy might be utilized to achieve better treatment outcomes.

\section{Abbreviations}

HR: Hazard ratio; RFS: Recurrence-free survival; UICC: Union for International Cancer Control.

\section{Competing interests}

The authors declare that they have no competing interests.

\section{Authors' contributions}

$\mathrm{MO}, \mathrm{HD}$, and $\mathrm{MI}$ carried out surgical resections. $\mathrm{MO}$, TS and $\mathrm{SH}$ revised the manuscript for important intellecutual content. YN carried out surgical resections and collected clinical data and designed this study and drafted the manuscript. All authors read and approved the final manuscript.

Received: 20 October 2012 Accepted: 9 May 2013

Published: 17 May 2013

\section{References}

1. Japanese Gastric Cancer Association: Japanese gastric cancer treatment guidelines 2010 (ver. 3). Gastric Cancer 2011, 14:113-123.

2. Sobin LH, Gospodarowicz MK, Wittekind C: (Eds): TNM Classification of Malignant Tumours. 7th edition. New York: Wiley-Blackwell; 2009.

3. Roukos DH, Lorenz M, Karakostas K, Paraschou P, Batsis C, Kappas AM: Pathological serosa and node-based classification accurately predicts gastric cancer recurrence risk and outcome, and determines potential and limitation of a Japanese-style extensive surgery for Western patients: a prospective with quality control 10-year follow-up study. Br J Cancer 2001, 84:1602-1609.

4. Roviello F, Marrelli D, de Manzoni G, Morgagni P, Di Leo A, Saragoni L, De Stefano A: Prospective study of peritoneal recurrence after curative surgery for gastric cancer. Br J Surg 2003, 90:1113-1119.

5. Schwarz RE, Zagala-Nevarez K: Recurrence patterns after radical gastrectomy for gastric cancer: prognostic factors and implications for postoperative adjuvant therapy. Ann Surg Oncol 2002, 9:394-400.

6. D'Angelica M, Gonen M, Brennan MF, Turnbull AD, Bains M, Karpeh MS: Patterns of initial recurrence in completely resected gastric adenocarcinoma. Ann Surg 2004, 240:808-816.

7. Yoo CH, Noh SH, Shin DW, Choi SH, Min JS: Recurrence following curative resection for gastric carcinoma. Br J Surg 2000, 87:236-242.

8. Marrelli D, Roviello F, de Manzoni G, Morgagni P, Di Leo A, Saragoni L, De Stefano A, Folli S, Cordiano C, Pinto E: Different patterns of recurrence in gastric cancer depending on Lauren's histological type: longitudinal study. World J Surg 2002, 26:1160-1165.

9. Zheng HC, Zheng YS, Xia P, Xu XY, Xing YN, Takahashi H, Guan YF, Takano $Y$ : The pathobiological behaviors and prognosis associated with Japanese gastric adenocarcinomas of pure WHO histological subtypes. Histol Histopathol 2010, 25:445-452.

10. Aoyama T, Yoshikawa T, Hayashi T, Kuwabara H, Mikayama Y, Ogata T, Cho $H$, Tsuburaya A: Risk factors for peritoneal recurrence in stage II/III gastric cancer patients who received S-1 adjuvant chemotherapy after D2 gastrectomy. Ann Surg Oncol 2012, 19:1568-1574.

11. Otsuji E, Yamaguchi T, Sawai K, Sakakura C, Okamoto K, Takahashi T: Regional lymph node metastasis as a predictor of peritoneal carcinomatosis in patients with Borrmann type IV gastric carcinoma. Am J Gastroenterol 1999, 94:434-437.

12. Kunisaki C, Shimada H, Nomura M, Matsuda G, Otsuka Y, Ono H, Akiyama H: Surgical outcome of serosa-negative advanced gastric carcinoma. Anticancer Res 2004, 24:3169-3175.

13. Lee HJ, Kim YH, Kim WH, Lee KU, Choe KJ, Kim JP, Yang HK: Clinicopathological analysis for recurrence of early gastric cancer. Jpn J Clin Oncol 2003, 33:209-214.

14. Saka M, Katai H, Fukagawa T, Nijjar R, Sano T: Recurrence in early gastric cancer with lymph node metastasis. Gastric Cancer 2008, 11:214-218

15. Ikeguchi M, Katano K, Oka A, Tsujitani S, Maeta M, Kaibara N: Relationship between hematogenic metastasis of gastric cancer and the maximum extent of venous invasion by cancer cells in the gastric wall. Hepatogastroenterology 1995, 42:660-665.

16. Noguchi Y: Blood vessel invasion in gastric carcinoma. Surgery 1990, 107:140-148.

17. Kodera Y, Ito S, Mochizuki Y, Yamamura Y, Misawa K, Ohashi N, Nakayama G, Koike M, Fujiwara M, Nakao A: The number of metastatic lymph nodes is a significant risk factor for bone metastasis and poor outcome after surgery for linitis plastica-type gastric carcinoma. World J Surg 2008, 32:2015-2020

18. Adachi $Y$, Kamakura T, Mori M, Baba H, Maehara Y, Sugimachi K: Prognostic significance of the number of positive lymph nodes in gastric carcinoma. Br J Surg 1994, 81:414-416. 
19. Saito H, Tsujitani S, Oka S, Kondo A, Ikeguchi M, Maeta M, Kaibara N: Prediction of survival period for patients with postoperative recurrence after curative resection for advanced gastric carcinoma. Hepatogastroenterology 2001, 48:290-293.

20. Nozoe T, Iguchi T, Egashira A, Adachi E, Matsukuma A, Ezaki T: Pathological prognostic score as a simple criterion to predict outcome in gastric carcinoma. J Surg Oncol 2010, 102:73-76.

21. Deng J, Liang H, Sun D, Pan Y: The prognostic analysis of lymph node-positive gastric cancer patients following curative resection. J Surg Res 2010, 161:47-53.

doi:10.1186/1477-7819-11-98

Cite this article as: Nakanishi et al: Differences in risk factors between patterns of recurrence in patients after curative resection for advanced gastric carcinoma. World Journal of Surgical Oncology 2013 11:98.

\section{Submit your next manuscript to BioMed Central and take full advantage of:}

- Convenient online submission

- Thorough peer review

- No space constraints or color figure charges

- Immediate publication on acceptance

- Inclusion in PubMed, CAS, Scopus and Google Scholar

- Research which is freely available for redistribution 